\title{
Emissions of persistent organic pollutants from transport in the experience of the Czech Republic
}

\author{
V. Adamec ${ }^{*}$, J. Dufek, J. Jedlička, R. Ličbinský \\ CDV - Transport Research Centre, Brno, Czech Republic \\ *Corresponding author: vladimir.adamec@cdv.cz
}

V. Bencko

Charles University in Prague, 1st Faculty of Medicine, Institute of Hygiene and Epidemiology, Czech Republic

\begin{abstract}
This presentation introduces the situation of POPs transport emissions in the Czech Republic since 1993, including a prediction for the years 2010 and 2015, determination of emission factors, possibilities for their reduction, and legislative framework. From the achieved results it is evident that the emissions from road and railway transport exceeded 28 tons in 2005. The naphtalene creates more than $90 \%$ of emissions of vehicles fulfilling EURO I-III limits. The phenanthrene (about $50 \%$ of PAHs) predominates in emissions of older gasoline vehicles that do not fulfil EURO limits; naphtalene content isabout $10 \%$. Total emissions of PCDDs and PCDFs are relatively low in the same context ofemissions of mostly older vehicles, manufactured before the acceptance of EURO limits. The potential health risks related to human exposure to transport emissions are the subject of interest of our present research.
\end{abstract}

KEYWORDS: polyaromatic hydrocarbons, polychlorinated biphenyls, polychlorinated dibenzo-dioxines, polychlorinated dibenzo-furanes, emissions, emission factors, air pollution, transport emissions.

\section{INTRODUCTION}

Over the past decades transport has become an important factor which affects the environment, both in a positive and a negative way. Besides traffic noise emission, the most serious problem is air pollution, especially due to its effect on human health, particularly in municipalities with dense motor vehicle traffic. Exhaust gases from motor vehicles contain hundreds of chemical substances in different concentrations and with a wide spectrum of potential health effects and related risks to human health (Bencko et al. 1994, 1996). Besides "classical" monitored pollutants, such as nitrogen oxides $\left(\mathrm{NO}_{\mathrm{X}}\right)$, carbon monoxide $(\mathrm{CO})$, carbon dioxide $\left(\mathrm{CO}_{2}\right)$ or sulphur dioxide $\left(\mathrm{SO}_{2}\right)$, recent attention has also been paid to human exposure to persistent organic pollutants (POPs) such as polycyclic aromatic hydrocarbons (PAHs), polychlorinated biphenyls (PCBs), polychlorinated dibenzop-dioxins (PCDDs) and polychlorinated dibenzofurans (PCDFs).

\section{METHODS}

With regard to the fact that POPs do not belong to the limited components of the traffic exhaust gases, determination of the emission factors of these pollutants is very limited. The situation is further complicated by the fact that values measured so far have a relatively 
large dispersion. The calculation and the audit of the amount of POPs emissions from transport was first stated in the following works: Ntziachristos and Samaras (2000), Krobl (2001) and Adamec et al. (2003a).

The emission factor (Ef) of a pollutant is always presented in the mass per the unit of energy $\left(\mathrm{g} \cdot \mathrm{MJ}^{-1}\right)$ ' the length of transport $\left(\mathrm{g} \cdot \mathrm{km}^{-1}\right)$, the mass of consumed fuel (g.kgfuel $\left.{ }^{-1}\right)$ or the power of the engine $\left(\mathrm{g} . \mathrm{kWh}^{-1}\right)$. Ef of limited pollutants, such as $\mathrm{CO}, \mathrm{NO}_{\mathrm{x}}$, hydrocarbons $\left(\mathrm{C}_{\mathrm{x}} \mathrm{H}_{\mathrm{y}}\right)$, or particular matters (PM), are compulsorily measured (periodical technical inspections), butthe measurement of POPs emissions from transport has so far not been controlled by any legislative directive. This is the reason why POPs emissions from vehicles are not usually measured and these measurements are especially connected with the experimental field. Forthis purpose, the authors made the database of Ef of selected POPs produced by transport (Dufek et al., 2002a). For an increase in the amount of reliable data, the authors performed a measurement campaign, with the collaboration of the Czech Motor Vehicle Research Institute, where the PAHs and dioxins were measured in Czech passenger cars. Results from national and foreign measurements, which are the sources, are continuously updated and evaluated statistically. The following Table 1 presents used emissions factors of selected POPs produced by transport which were used for the elaboration of the emission inventory. Calculations of total emissions used average values for each category of means of transport.

Table 1: Emission factors of selected POPs produced by transport (Dufek \& Adamec, 2002a)

\begin{tabular}{|l|c|c|c|}
\hline \multirow{2}{*}{ Vehicle category } & PAH total & PCDD & PCDF \\
\cline { 2 - 4 } & $\mathbf{H g . k m}^{\mathbf{- 1}}$ & $\mathbf{p g}^{\mathbf{k}} \mathbf{k m}^{\mathbf{- 1}}$ & $\mathbf{~ p g . k m}^{\mathbf{- 1}}$ \\
\hline motorcycles & 131.64 & 10.3 & 21.2 \\
\hline gasoline conventional cars & 260.29 & 10.3 & 21.2 \\
\hline gasoline cars fulfilling EURO standards & 143.84 & - & - \\
\hline diesel passenger cars & 1277.44 & 0.5 & 1.0 \\
\hline LPG passenger cars & 49.46 & - & - \\
\hline gasoline light duty vehicles & 378.11 & 10.3 & 21.2 \\
\hline diesel light duty vehicles & 1601.16 & 0.5 & 1.0 \\
\hline diesel heavy duty vehicles & 241.86 & 3.0 & 7.9 \\
\hline
\end{tabular}

\section{RESULTS AND DISCUSSION}

For the determination of POPs emissions methodology for the calculation of air polluting emissions from transport was applied (Dufek \& Adamec, 2002b) which uses data about the amount of sold fuels. After the deduction of non-transport sources, i.e., diesel fuel consumption in farming, forestry, civil engineering and the army (especially concerning diesel), the amount of sold fuel is split by means of transport performances into particular modes of transport:

- Individual road passenger transport (IPT)

- Public road passenger transport (RPT)

- Road freight transport (RFT)

- Railway transport - motor traction (RWT)

- Waterway transport (WWT)

- Air transport (AIR).

The split of individual fuels is carried out with the help of weighing factors based on transport performances and annual mileages from the national transport statistics. The national traffic census on motorway and road network is the most important and it is carried out once every five years. Transport emissions - producing vehicles are split into 
specific categories according to the transport mode, fuel used and equipment with catalytic converters. From this split in consumption, emissions are calculated by means of average emission factors. For each of the given categories the averaged emission factor (g.kgfuel-1) is used, which is based on the measured and statistically processed values. For an elaboration of emission inventory consumptions of particular fuels were used, determined bythe aforementioned methodology and emission factors, presented in Table 1, evaluated statistically in the database of emission factors, and recalculated from g.km-1 to g.kgfuel-1. The emission inventory includes emissions for PAHs, PCDDs, PCDFs, and PCBs.

Emissions from air transport are not included in the aforementioned emission audit because the authors had no access to pertinent data concerning the PAHs in emissions of hydrocarbons produced by combustion of airplane fuels.

Table 2: Total PAHs emissions in the Czech Republic (t)

\begin{tabular}{|l|c|c|c|c|c|c|c|c|c|c|c|c|c|c|c|}
\hline $\begin{array}{c}\text { Mode } \\
\text { of } \\
\text { transport }\end{array}$ & $\mathbf{1 9 9 3}$ & $\mathbf{1 9 9 4}$ & $\mathbf{1 9 9 5}$ & $\mathbf{1 9 9 6}$ & $\mathbf{1 9 9 7}$ & $\mathbf{1 9 9 8}$ & $\mathbf{1 9 9 9}$ & $\mathbf{2 0 0 0}$ & $\mathbf{2 0 0 1}$ & $\mathbf{2 0 0 2}$ & $\mathbf{2 0 0 3}$ & $\mathbf{2 0 0 4}$ & $\mathbf{2 0 0 5}$ & $\mathbf{2 0 1 0}$ & $\mathbf{2 0 1 5}$ \\
\hline IPT & 6.13 & 6.64 & 7.11 & 8.25 & 8.54 & 8.59 & 9.22 & 9.45 & 10.48 & 10.99 & 13.03 & 14.41 & 16.90 & 17.34 & 17.50 \\
\hline RPT & 0.33 & 0.17 & 0.19 & 0.20 & 0.18 & 0.27 & 0.27 & 0.58 & 0.63 & 0.66 & 0.76 & 0.82 & 0.95 & 1.13 & 1.34 \\
\hline RFT & 2.22 & 3.00 & 4.00 & 5.21 & 5.81 & 5.16 & 5.57 & 6.04 & 6.68 & 6.92 & 8.17 & 9.04 & 10.59 & 11.12 & 11.24 \\
\hline RWT & 0.20 & 0.16 & 0.23 & 0.25 & 0.21 & 0.19 & 0.15 & 0.10 & 0.09 & 0.09 & 0.09 & 0.09 & 0.09 & 0.08 & 0.07 \\
\hline WWT & 0.03 & 0.02 & 0.03 & 0.04 & 0.02 & 0.02 & 0.01 & 0.01 & 0.01 & 0.00 & 0.00 & 0.01 & 0.01 & 0.01 & 0.01 \\
\hline Total & 8.91 & 10.10 & 11.70 & 14.12 & 14.93 & 14.46 & 15.22 & 16.19 & 17.89 & 18.66 & 22.05 & 24.37 & 28.54 & 29.68 & 30.16 \\
\hline
\end{tabular}

According to our calculations, (Adamec et al. 2003a) the yearly amount of PAHs emissions in the Czech Republic from transport exceeded 28 tons in 2005. The prediction is also quite negative: due to the continuing increase of diesel oil consumption, growth of PAHs emissions is predicted to reach 30 tons in 2015. However, the increase is lower than the supposed traffic increase, because new cars are less pollution-emitting than older ones. The naphthalene creates more than $90 \%$ of PAHs emissions from gasoline vehicles, which meet EURO emission limits, and from diesel vehicles. The phenanthrene (about $50 \%$ of PAHs) predominates in emissions from older petrol vehicles which do not meet EURO emission limits; naphthalene content is less than $10 \%$ in the case of these vehicles. We find by comparing PAHs emission factors from various sources that there are not such strong differences between newer and older vehicles as in the case of VOC, because PAHs are not limited by any standards.

Table 3: Total PCDDs emissions in the Czech Republic (mg)

\begin{tabular}{|c|c|c|c|c|c|c|c|c|c|c|c|c|c|c|c|}
\hline \multirow{2}{*}{$\begin{array}{c}\begin{array}{c}\text { Mode } \\
\text { of } \\
\text { transport }\end{array} \\
\end{array}$} & \multicolumn{15}{|c|}{ Year } \\
\hline & 1993 & 1994 & 1995 & 1996 & 1997 & 1998 & 1999 & 2000 & 2001 & 2002 & 2003 & 2004 & 2005 & 2010 & 2015 \\
\hline IPT & 195.1 & 214.9 & 209.6 & 219.9 & 211.2 & 178.1 & 163.3 & 116.3 & 105.6 & 81.9 & 77.7 & 66.1 & 54.5 & 52.2 & \\
\hline RPT & 3.4 & 3.7 & 4.5 & 4.8 & 4.5 & 5.8 & 5.5 & 4.4 & 4.8 & 4.8 & 5.6 & 6.1 & 7.0 & 8.1 & 8.4 \\
\hline RFT & 17.9 & 29.0 & 32.9 & 38.1 & 45.8 & 37.0 & 37.0 & 12.0 & 13.1 & 13.1 & 15.3 & 16.7 & 19.3 & 22.0 & 22.6 \\
\hline RWT & 2.4 & 2.0 & 2.9 & 3.1 & 2.5 & 2.6 & 2.3 & 1.2 & 1.2 & 1.1 & 1.1 & 1.1 & 1.1 & 0.9 & 0.5 \\
\hline WWT & 0.3 & 0.3 & 0.4 & 0.5 & 0.2 & 0.3 & 0.3 & 0.1 & 0.1 & 0.0 & 0.0 & 0.1 & 0.1 & 0.1 & 0.1 \\
\hline Total & 219.1 & 249.9 & 250.3 & 266.4 & 264.2 & 223.8 & 208.4 & 134.0 & 124.8 & 100.9 & 99.7 & 90.1 & 82.0 & 83.3 & 83.4 \\
\hline
\end{tabular}


Table 4: Total PCDFs emissions in the Czech Republic (mg)

\begin{tabular}{|l|r|r|r|r|r|r|r|r|r|r|r|r|r|r|r|}
\hline \begin{tabular}{c} 
Mode $\begin{array}{c}\text { of } \\
\text { transport }\end{array}$ \\
\cline { 2 - 17 }
\end{tabular} & $\mathbf{1 9 9 3}$ & $\mathbf{1 9 9 4}$ & $\mathbf{1 9 9 5}$ & $\mathbf{1 9 9 6}$ & $\mathbf{1 9 9 7}$ & $\mathbf{1 9 9 8}$ & $\mathbf{1 9 9 9}$ & $\mathbf{2 0 0 0}$ & $\mathbf{2 0 0 1}$ & $\mathbf{2 0 0 2}$ & $\mathbf{2 0 0 3}$ & $\mathbf{2 0 0 4}$ & $\mathbf{2 0 0 5}$ & $\mathbf{2 0 1 0}$ & $\mathbf{2 0 1 5}$ \\
\hline IPT & 403.2 & 444.4 & 433.3 & 454.6 & 436.6 & 368.2 & 338.0 & 240.2 & 218.1 & 169.0 & 160.3 & 136.2 & 112.1 & 107.2 & 105.6 \\
\hline RPT & 4.9 & 4.2 & 5.1 & 5.3 & 4.9 & 6.3 & 6.1 & 4.4 & 4.8 & 4.8 & 5.6 & 6.1 & 7.0 & 8.1 & 8.4 \\
\hline RFT & 32.8 & 54.7 & 61.3 & 69.9 & 84.5 & 67.6 & 80.0 & 12.0 & 13.1 & 13.1 & 15.3 & 16.7 & 19.3 & 22.0 & 22.6 \\
\hline RWT & 2.4 & 2.0 & 2.9 & 3.1 & 2.5 & 2.6 & 2.3 & 1.2 & 1.2 & 1.1 & 1.1 & 1.1 & 1.1 & 0.9 & 0.9 \\
\hline WWT & 0.3 & 0.3 & 0.4 & 0.5 & 0.2 & 0.3 & 0.3 & 0.1 & 0.1 & 0.0 & 0.0 & 0.1 & 0.1 & 0.1 & 0.1 \\
\hline Total & 443.6 & 505.6 & 503.0 & 533.4 & 528.7 & 445.0 & 426.7 & 257.9 & 237.3 & 188.0 & 182.3 & 160.2 & 139.6 & 138.3 & 137.6 \\
\hline
\end{tabular}

PCDDs and PCDFs emissions from transport reach totally milligrams. They are mostly produced by older vehicles which do not meet EURO 1-3 emission limits. The downward trend in the production of these emissions from transport is caused by renewal of the vehicle fleet, especially in the individual road passenger transport. From the COPERT database of emission factors it is not possible to ascertain if these emissions from older vehicles are fixed on the halogenated scavengers or if they originate from trace amounts of chlorine in the petrol.

Emission factors of PCDDs and PCDFs are very low, in pg. $\mathrm{km}^{-1}$, and hence it is also probable the origin of this minimum amount is by burning fuels which do not contain halogenated scavengers. This assumption is also supported by the fact that the database includes emission factors of diesel vehicles as well, where halogenated ingredients were not applied. Nevertheless a suspicion that polyhalogenated hydrocarbons from exhaust emissions can contribute to a total human exposure to this kind of xenobiotics was raised from results of the analyses of breast milk samples collected at places with extremely high traffic density (Bencko et al. 2004).

Table 5: Total PCBs emissions in the Czech Republic (mg) - gasoline vehicles

\begin{tabular}{|l|r|r|r|r|r|r|r|r|r|r|r|r|r|r|r|}
\hline \begin{tabular}{c} 
Mode $\begin{array}{c}\text { of } \\
\text { transport }\end{array}$ \\
\cline { 2 - 17 }
\end{tabular} & $\mathbf{1 9 9 3}$ & $\mathbf{1 9 9 4}$ & $\mathbf{1 9 9 5}$ & $\mathbf{1 9 9 6}$ & $\mathbf{1 9 9 7}$ & $\mathbf{1 9 9 8}$ & $\mathbf{1 9 9 9}$ & $\mathbf{2 0 0 0}$ & $\mathbf{2 0 0 1}$ & $\mathbf{2 0 0 2}$ & $\mathbf{2 0 0 3}$ & $\mathbf{2 0 0 4}$ & $\mathbf{2 0 0 5}$ & $\mathbf{2 0 1 0}$ & $\mathbf{2 0 1 5}$ \\
\hline IPT & 169.0 & 190.1 & 192.4 & 212.0 & 218.8 & 204.7 & 224.4 & 226.5 & 222.4 & 218.2 & 237.7 & 235.5 & 231.3 & 216.9 & 212.6 \\
\hline RPT & 0.3 & 0.4 & 0.4 & 0.4 & 0.3 & 0.4 & 0.4 & 0.4 & 0.5 & 0.6 & 0.7 & 0.8 & 0.9 & 1.1 & 1.3 \\
\hline RFT & 10.0 & 17.5 & 19.1 & 21.2 & 26.0 & 20.3 & 24.7 & 26.1 & 26.9 & 31.3 & 28.4 & 28.2 & 27.5 & 25.6 & 24.9 \\
\hline RWT & 0.1 & 0.1 & 0.1 & 0.1 & 0.1 & 0.1 & 0.1 & 0.1 & 0.1 & 0.1 & 0.1 & 0.1 & 0.1 & 0.1 & 0.1 \\
\hline WWT & 0.0 & 0.0 & 0.0 & 0.0 & 0.0 & 0.0 & 0.0 & 0.0 & 0.0 & 0.0 & 0.0 & 0.0 & 0.0 & 0.0 & 0.0 \\
\hline Total & 179.4 & 208.1 & 212 & 233.7 & 245.2 & 225.5 & 249.6 & 253.1 & 249.9 & 250.2 & 266.9 & 264.6 & 259.8 & 243.7 & 238.9 \\
\hline
\end{tabular}

Note: PCBs emissions were calculated only for gasoline vehicles because no measurements of emission factors of PCBs of diesel vehicles were found.

\section{CONCLUSIONS}

POPs emissions from mobile sources are high due to the large proportion of older vehicles on the road in the Czech Republic. Only their replacement by up-to-date vehicles, equipped with suitable technologies for the reduction of POPs, will contribute to a decrease in their total production. 
The PAHs and POPs emissions are a part of the total hydrocarbon emissions that are limited by UN ECE standards. The PAHs themselves are not limited by any specific emission standard or environmental limit and so their emissions are not regularly checked. Their significant increase in the Czech Republic was detected in 1993 and has continued up tothepresent day. This fact represents a threat to air quality and demonstrates the increase ofthe potential adverse impact of traffic emissions on human health.

Our main health interest in a current project dealing with solid aerosols in traffic emissions is oriented due to our previous experience (Bencko \& Reichrtová, 1992; Reichrtová $\&$ Bencko, 1996) on immunity aspects in this context.

\section{ACKNOWLEDGEMENTS}

The study was supported by the Czech Ministry of Transport, within research projects R\&D Nr. 801/210/109 "Research of Environmental Burden from Transport" and 1F54H/098/520 "The dust from traffic and its impact on airborne emission loading with suspended particles".

\section{REFERENCES}

Adamec, V., Dufek, J., Jedlička, J., Cholava, R., 2003a. Persistent organic pollutants in transport sector. In. Robert Joumard. 12th Symposium "Transport \& Air pollution" volume 2. Arcueil: INRETS, p. 209 - 212. ISBN 2-85782-588-9.

Adamec, V., Dufek, J., Huzlík, J., Cholava, R., Jedlička, J., Klustová, P., Marešová, V.,Šucmanová, M., 2003b. Research of Environmental Burden from Transport. Brno: CDV, 200 p. (In Czech).

Bencko, V. \& Reichrtová, E., 1992. Immunological Aspects of Exposure to Exhaust Gases. In: Proc. International Workshop on Human Health and Environmental Effects of Motor Vehicle Fuels and their Exhaust Emissions, Sydney, Australia, pp. 185-191.

Bencko, V., Tuček, M., Volný, J., 1994. Health Aspects of Human Exposure to Exhaust Gases. In: Proc. XIV Asian Conference on Occupational Health. Beijing, China: pp. 423.

Bencko, V., Šuta, M., Tuček, M., Volný, J., 1996. Health Aspects of Human Exposure to Oxidants and Exhaust Gases. In: Proc. Indoor Air 1996, Nagoya, Japan: pp. 1137-1142.

Bencko, V., Černá, M., Jech, L., Šmíd, J., 2004. Exposure of Breast-fed children in the Czech Republic to PCDDs, PCDFs, and Dioxin-like PCBs. Environmental Toxicology and Pharmacology, vol.18, pp. 83-90.

Dufek, J. \& Adamec, V., 2002a. Database of Measured Emission Factors from Transport Sector. CDV, Brno, Czech Republic (In Czech).

Dufek J. \& Adamec, V., 2002b. Methodology of the Calculation of Air Polluting Emissions for All Transport Modes. CDV, Brno, Czech Republic, 24 p. (In Czech).

Krobl L., 2001. Survey of Emission Factors of Road Motor Vehicles. ÚVMV, Prague, Czech Republic, 35 p. (In Czech).

Ntziachristos L. \& Samaras, Z., 2000. COPERT III - Computer Programme to Calculate Emissions from Road Transport. Methodology and Emission Factors (Version 2.1). EEA, Copenhagen, Denmark, $84 \mathrm{p}$.

Reichrtová, E. \& Bencko, V., 1996. Immune Response to Exhaust Gases Derived from Two Cycle Combustion Engine Following Experimental Exposure. Centr. eur. J. publ. Health, vol.4. pp 4-10. 
USEPA, 2000. Exposure and Human Health Reassessment of 2,3,7,8-Tetrachlorodibenzo-pDioxin (TCDD) and Related Compounds. Part I: Estimating Exposure to Dioxin-Like Compounds. Volume 2: Sources of Dioxin-Like Compounds in the United States. (draft) [online]. Accessible on site http://cfpub.epa.gov/ncea/cfm/part1and2.cfm?ActType=default (cit. 2005-May-11).

USEPA, 2001. Database of Sources of Environmental Releases of Dioxin-like Compounds in the United States. Version 3.0. (EPA/600/C01/012) [online]. Accessible on site http://cfpub.epa.gov/ncea/cfm/dioxindb.cfm (cit. 2005-05-11).

WHO, 2000. Guidelines for air quality. Geneva, Switzerland, WHO.

WHO, 2000a. Air Quality Guidelines for Europe, Second Edition. Regional Publications, European Series, No. 91. Geneva, Switzerland, WHO, 288 p., ISBN 92-890-1358-3. 